\title{
A New Process for the recovery of bio-accumulated cadmium from Scallops
}

\author{
Kedar Nath Ghimire* \\ Central Department of Chemistry, Tribhuvan University, Kirtipur, Kathmandu \\ Email: knghimire@yahoo.com
}

\begin{abstract}
A novel process for cadmium recovery from mid gut of scallops is investigated based on the systematic information of the process system. Adsorption of cadmium was accompanied according to the cation exchange mechanism and the equilibrium $\mathrm{pH}$ increased to around 7 due to the isomorphous substitution of cadmium with that calcium of SAJR. A complete recovery of cadmium has been achieved from the process that we have developed from this study.
\end{abstract}

Keywords: Cadmium, Adsorption, Cation exchange, Scallops

\section{Introduction}

Scallop is extensively aqua-cultured in northern part of Japan. Only edible parts are shipped to the market while the midgut gland, which is considered as waste are left at the fishing sites. These wastes contain considerably large amount of bio-accumulated cadmium. The treatment of these wastes now is a serious local problem. In some sites they are incinerated, but the ash containing significant amounts of cadmium is still a matter of problem. On the other hand, these wastes contain large amount of high quality proteins, aminoacids, fats and fatty acids such as decosahexanoic acid and eicosapentanoic acid as well as minerals such as calcium and phosphorus ${ }^{1}$. Consequently, there is a possibility that they can be converted into valuable resources depending on the methods of treatments. However, the heavy metals contained impede the above mentioned effective use of wastes. Although some works have been conducted about the removal of heavy metals from scallops, information regarding their treatment procedures is still limited ${ }^{2,3,4,5}$. For this purpose, a new method has been developed for the recovery of bio-accumulated cadmium from scallop wastes.

\section{Materials and methods}

\section{Leaching at constant $\mathrm{pH}$ :}

$100 \mathrm{~g}$ of fresh uro were spread on the plastic net and dipped into the solution of $1000 \mathrm{~mL} 0.05$ $\mathrm{mol} / \mathrm{dm}^{3}$ sulphuric acid at around $\mathrm{pH} 1.5$. The solution was stirred with magnetic stirrer without contacting the Uro kept on the plastic filter net. The $\mathrm{pH}$ of the solution was monitored at each interval of time and kept the suspension $\mathrm{pH}$ constant at 1.5 by adding additional sulphuric acid at a temperature of $30^{\circ} \mathrm{C}$. It has shown that after $24 \mathrm{~h}$, all the cadmium was leached out from the uro which had been recognized by measuring the cadmium concentration in leach liquor and the uro residue solution itself prepared in aqua regia. This way the concentration of cadmium in leach liquor was $2.64 \mathrm{mg} / \mathrm{L}$.

\section{* Corresponding author}




\section{Leaching of additional fresh Uro with the leachate solution itself}

About 200g of fresh uro were spread on the plastic net and kept into the fresh leach liquor of Uro as mentioned in the above process. After leaching around 4 hours, the $\mathrm{pH}$ increased around 4 and the concentration of cadmium upto $3.2 \mathrm{mg} / \mathrm{L}$. This solution was taken for the adsorption experiment onto AJR.

\section{Results and discussion}

\section{Adsorption of cadmium from leach liquor onto SAJR}

1) $600 \mathrm{mg}$ of AJR and $50 \mathrm{~mL}$ of leach liquor containing $3.2 \mathrm{mg} / \mathrm{L}$ cadmium were equilibrated into six $50 \mathrm{~mL}$ conical flasks separately at $\mathrm{pH} 4.01$. The amount of AJR with the leach liquor kept constant at 12 $\mathrm{g} / \mathrm{Kg}$ solid liquid ratio in these experiments of the fact that $100 \%$ of cadmium could be adsorbed at this solid liquid ratio. The flasks were shaken vigorously in a thermostated shaker at $30^{\circ} \mathrm{C}$ for $24 \mathrm{~h}$. The residual concentration of the cadmium in the filtrate was measured by ICPMS 8100 spectrometer. It is observed that all the cadmium was adsorbed onto the gel.

2) For comparison, a similar sets of experiment was carried out by taking leach liquor obtained through constant $\mathrm{pH}$ leaching and maintained the $\mathrm{pH}$ at 4.01 by adding sodium hydroxide. The initial concentration of such liquor was $2.64 \mathrm{mg} / \mathrm{L} .1 .6 \mathrm{~mL}$ of $10 \%$ Kakishibu was used for each $50 \mathrm{~mL}$ sample after adsorption of cadmium onto AJR prior to the filtration.

\section{Elution of cadmium from AJR}

After filtration the cadmium loaded AJR mentioned above in step i) and step2) were collected separately and dried in vacuo for $12 \mathrm{~h}$. The dried cadmium loaded AJR was equilibrated with $50 \mathrm{~mL}$ of 0.1 $\mathrm{mol} / \mathrm{dm} 3$ sulphuric acid and shaken vigorously in a thermostated shaker for $24 \mathrm{~h}$. The cadmium eluted from AJR was monitored using ICPMS 8100 spectrometer. The cadmium eluted from the step 1 sample was $18.84 \mathrm{mg} / \mathrm{L}$, while that from the step 2 was $15.5 \mathrm{mg} / \mathrm{L}$, respectively. The cadmium recovery therefore is equivalent to the $98 \%$ and $97.85 \%$, respectively. Since a complete adsorption and elution of cadmium has been achieved, the small error could be due to handling of AJR during filtration process and sample lost during collection. But this small error can be neglected.

\section{Precipitation}

In an attempt to recover the eluted cadmium, precipitation test was carried out using sodium sulphide and calcium hydroxide; respectively. Both the medium could completely precipitate the cadmium from the solution. It is important to be pointed out here that the amount of sodium sulphide to precipitate as sulphides and the $\mathrm{pH}$ of the solution using calcium hydroxide were the deciding factor. After precipitation, the suspension was filtered and the cadmium concentration was measured by ICPMS 8100 Spectrometer. The filtrate did not contain any cadmium confirming that all the metal ions were precipitated.

\section{Conclusion}

A novel process for cadmium recovery from mid gut of scallops is investigated based on the systematic information of the process system. Initially, cadmium from such scallops waste were extracted using $0.05 \mathrm{~mol} / \mathrm{dm}^{3}$ sulphuric acid and during extraction process the leach liquor $\mathrm{pH}$ was kept constant at 1.5 by adding additional sulphuric acid. Such leach liquor of $\mathrm{pH} \sim 1.5$ was further drained to another container that contained $200 \mathrm{~g}$ of fresh waste scallops. This led to the increase in $\mathrm{pH}$ by the Uro itself and finally subjected to adsorption onto saponificated apple juice residue (SAJR) at a solid/liquid ratio of $12 \mathrm{~g} / \mathrm{L}$. A complete adsorption of cadmium was accompanied according to the cation exchange 
mechanism and the equilibrium $\mathrm{pH}$ increased to around 7 due to the isomorphous substitution of cadmium with that calcium of SAJR. The $\mathrm{pH}$ increment with the introduction of fresh uro could be due to the adsorption of protons from the acidic leach liquor by the available peptides within the Uro and the dissolution of other metal ions like magnesium in the leachate. The adsorbed cadmium was recovered by equilibrating with $0.1 \mathrm{~mol} / \mathrm{dm}^{3}$ sulphuric acid for $24 \mathrm{~h}$ at $30^{\circ} \mathrm{C}$ in a thermostatic shaker. A complete cadmium recovery from this process was achieved which is given in the process figure.

\section{References}

1. O. Tavakoli and H. Yoshida, Environ. Sci. Technol., 39, 2357-2363(2005).

2. T. Obara, TSawaya, K. Hikori, Y. Umehara, M. Mizukami and F. Tomita, Biosci. Biotechnol. Biochem., 63, 500-505(1999).

3. G. M. Kruzynski, Toxicol. Lett., 148, 159-169(2004).

4. Y. Sakuta and K. Shimakage, Journal of MMIJ, 120, 71-77(2004).

5. K. Inoue, K. N. Ghimire. K. Huang, K. Ohto, H. Harada, H. Kawakita and M. Morita, Jpn. Soc. Waste Manag. Expert., 17, 299-304(2006).

1. Steps of leaching accompanying pH adjustment by uro itself

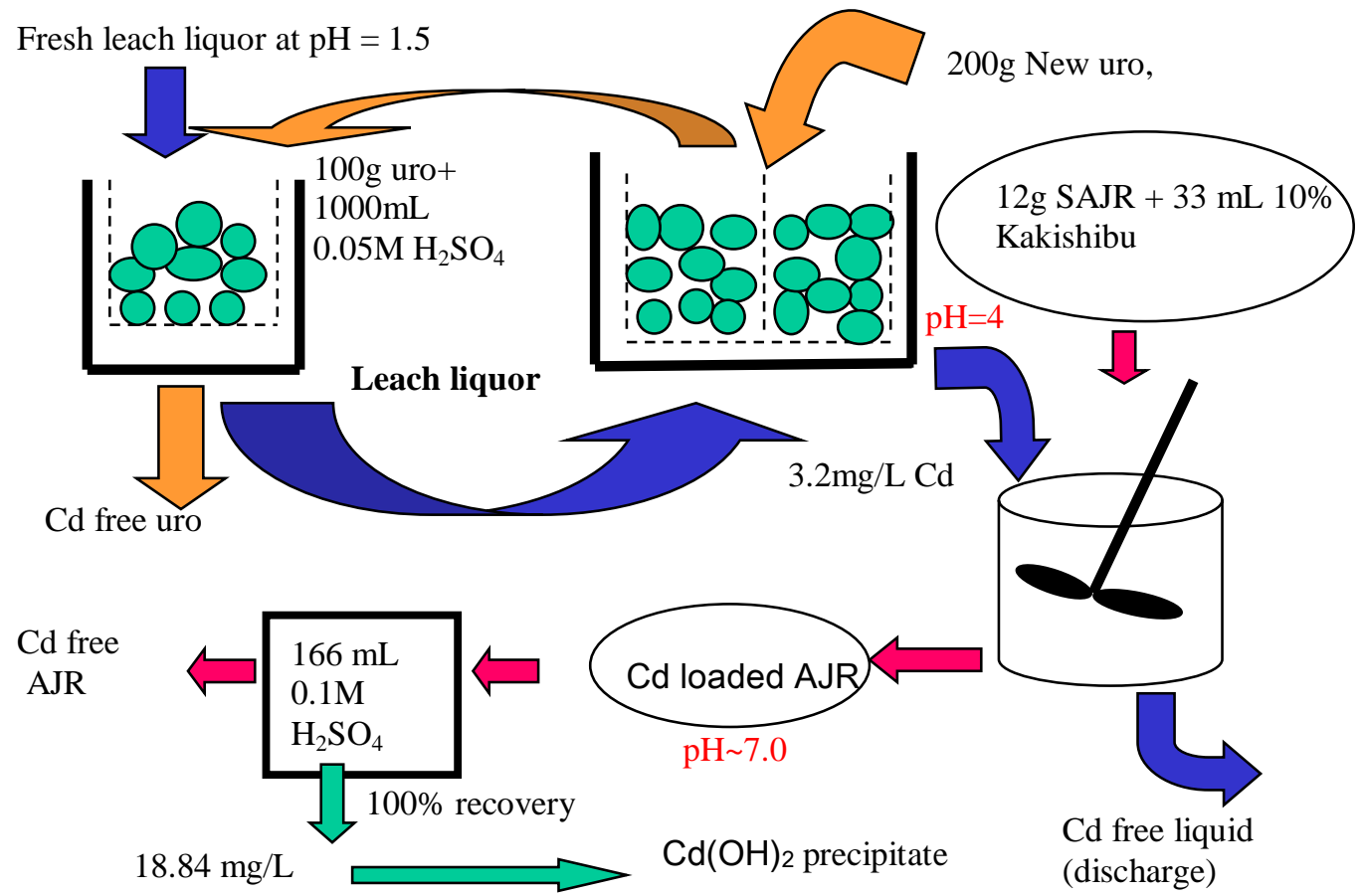


2. Steps of leaching followed by coagulation/precipitation

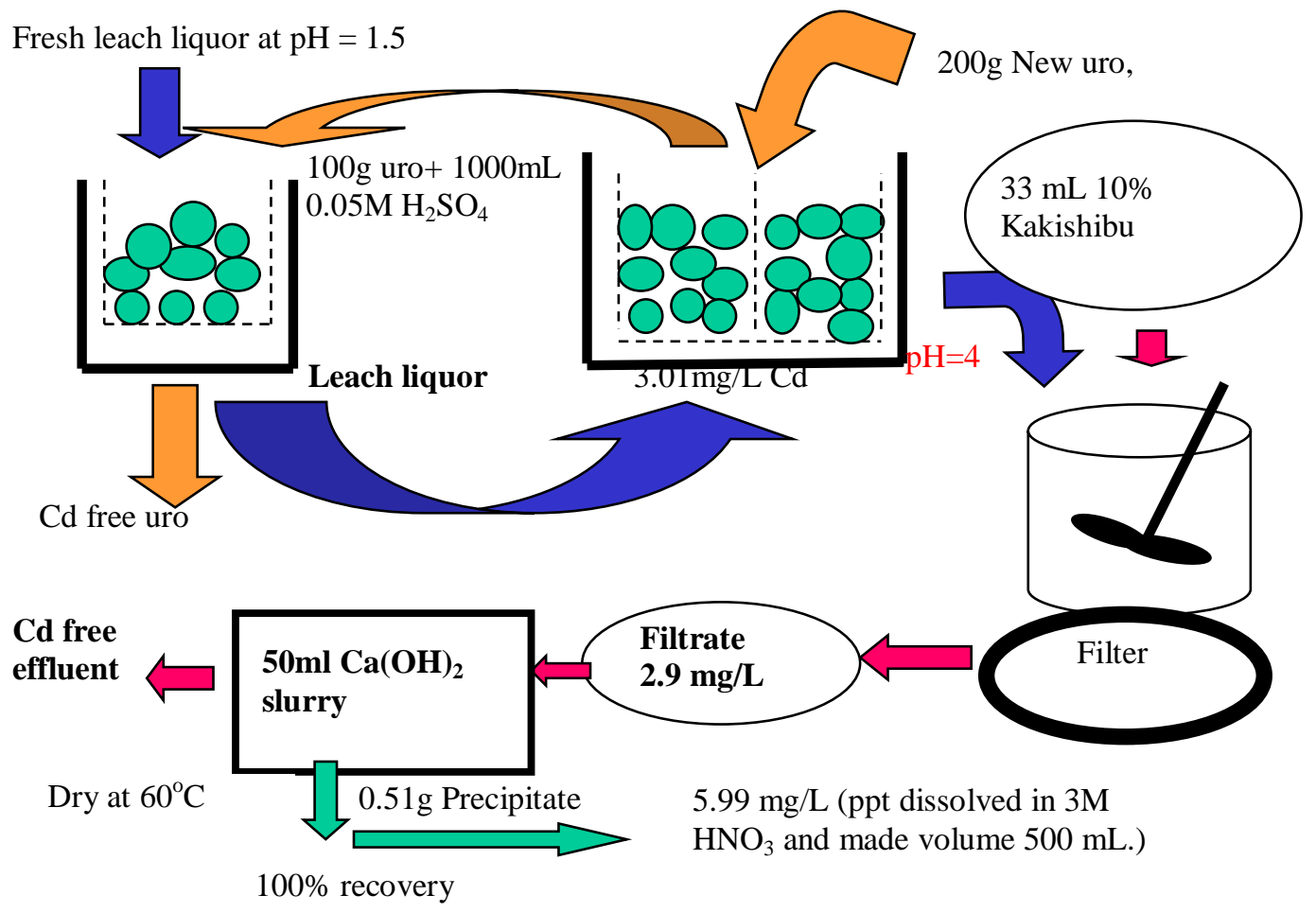

